\title{
Effects of Late Preterm Birth on the Incidence of Developmental Delays among Children at 3 Years of Age: A Matched-Pair Case-Control Study
}

\author{
Tomohiro Oba $^{{ }^{*}}$, Junichi Hasegawa ${ }^{1}$, Katsufumi Otsuki ${ }^{2}$, Kazuo Itabashi ${ }^{3}$, Takashi Okai ${ }^{1}$, \\ Akihiko Sekizawa ${ }^{1}$ \\ ${ }^{1}$ Department of Obstetrics and Gynecology, Showa University, School of Medicine, Tokyo, Japan \\ ${ }^{2}$ Department of Obstetrics, Showa University Koto Toyosu Hospital, Tokyo, Japan \\ ${ }^{3}$ Division of Neonatology, Department of Pediatrics, Showa University School of Medicine, Tokyo, Japan \\ Email: tomo008hero@yahoo.co.jp
}

Received 13 March 2015; accepted 3 April 2015; published 8 April 2015

Copyright (C) 2015 by authors and Scientific Research Publishing Inc.

This work is licensed under the Creative Commons Attribution International License (CC BY). http://creativecommons.org/licenses/by/4.0/

(c) (i) Open Access

\begin{abstract}
Purpose: To investigate the relationship between preterm delivery and developmental outcomes in children born at 34 - 36 weeks of gestation (late preterm period). Methods: This study reviewed the cases of singleton late preterm children and full-term (38 - 40 weeks of gestation) children born at Showa University Hospital. The developmental outcomes at 3 years of age were assessed based on the results of questionnaires sent to the families by mail. In addition, the incidence of developmental delays was compared between the late preterm and full-term children. In the fullterm control group, perinatal characteristics (neonatal gender, Apgar score, Cesarean delivery, birth weight $<10$ th percentile, birth weight $<3$ rd percentile) were matched with those of the late preterm cases. We compared categorical variables using Fisher's exact test. For variables with a non-normal distribution, Welch's $t$-test was applied. A p-value of $<0.05$ was considered to be statistically significant. Results: The rate of return of the questionnaires was $25.9 \%$ (121) among the cases and $25.8 \%(163)$ among the controls. The frequency of developmental delays was $6.6 \%$ among the cases, compared with $4.3 \%$ among the controls. Conclusions: Matching the perinatal characteristics of the subjects, the frequency of developmental delays was similar between the two groups.
\end{abstract}

\section{Keywords}

Developmental Outcome, Fetal Growth Restriction, Late Preterm, Non-Reassuring Fetal Status,

\footnotetext{
*Corresponding author.
}

How to cite this paper: Oba, T., Hasegawa, J., Otsuki, K., Itabashi, K., Okai, T. and Sekizawa, A. (2015) Effects of Late Preterm Birth on the Incidence of Developmental Delays among Children at 3 Years of Age: A Matched-Pair Case-Control Study. Open Journal of Obstetrics and Gynecology, 5, 203-207. http://dx.doi.org/10.4236/ojog.2015.54029 


\section{Preterm Delivery, Perinatal Characteristics}

\section{Introduction}

In recent years, remarkable improvements have been observed in the field of neonatology, thus resulting in better short-term prognoses among late preterm infants in most cases. In addition, the need to terminate the pregnancy is often assessed during the late preterm period in order to avoid sudden aggravation of maternal complications, such as preeclampsia, and fetal complications, such as a non-reassuring fetal status or intrauterine fetal death. On the other hand, evidence suggests that, although the frequency of an abnormal state during the neonatal period has decreased, late preterm children are at risk of developmental delays over the long term [1]-[3]. Therefore, obstetricians should determine the timing of delivery taking into consideration long-term developmental outcomes.

However, it is possible that more late preterm infants exhibit perinatal characteristics that adversely affect developmental outcomes compared to full-term infants. It is also unclear whether the poor long-term developmental outcomes of late preterm children are caused by the timing of delivery in the late preterm period itself or rather the incidence of perinatal complications during the period of delivery. We hypothesized that a lack of differences in the perinatal characteristics between late preterm and full-term children would result in a lack of differences in developmental outcomes between these groups. Therefore, the aim of the present study was to clarify the effects of late preterm birth on the developmental outcomes observed at 3 years of age, regardless of perinatal complications. We suppose the study significant for obstetricians to determine the timing of delivery at late preterm period.

\section{Materials and Methods}

We sent letters to the all parents of singleton children born at 34 - 36 weeks of gestation (late preterm period) at Showa University Hospital, Tokyo between January 2003 and October 2010, requesting the participation in this study. Only cases who consent to the participation were enrolled (cases). After obtaining the perinatal characteristics from the patients' medical reports, a case-control study with matched pairs was conducted. We chose randomly the same number of singleton children born at 38 - 40 weeks of gestation (full-term) at our hospital during the same study period with matching perinatal characteristics (gender, Apgar score, Cesarean delivery, birth weight $<10$ th percentile, birth weight $<$ 3rd percentile).We sent letters to the parents of full term children in the same way, and only cases who consent to the participation were enrolled (controls). Infants with congenital anomalies, hearing loss or chromosomal defects were excluded from the study.

Questionnaires were then sent with a stamped return envelope to the parents of the subjects inquiring about the developmental outcomes observed at 3 years of age. Only patients whose development was assessed by a pediatrician at 3 years of age were enrolled.

The incidence of developmental delays at 3 years of age was subsequently compared between the cases and controls. A developmental delay was defined as a diagnosis of a developmental delay at 3 years of age requiring therapy with special supportive programs. In contrast, normal development was diagnosed when the family reported normal developmental checkup findings at 3 years of age and indicated no developmental problems on the questionnaire.

The statistical analysis was performed using the JMP® Version 10 software program. We compared categorical variables between two groups using Fisher's exact test. For variables with a non-normal distribution, Welch's $t$-test was applied. A $p$-value of $<0.05$ was considered to be statistically significant. The study protocol was approved by the ethics board of Showa University. Informed consent was obtained from each patient's parent or legal guardian.

\section{Results}

Among 8276 children born during the study period, 469 (5.7\%) were born during the late preterm period. The rate of response to the questionnaires was 29.2\% (136) among the cases and $29.0 \%$ (184) among the controls.

We excluded subjects for whom answers were indistinct or records of the developmental checkup at 3 years 
of age were missing. Ultimately, 121 cases and 163 controls were enrolled in the present study.

The maternal and neonatal demographics of the cases and controls are shown in Table 1 . The birth weight was $2900 \pm 429$ in the controls and $2289 \pm 469$ in the cases $(p<0.001)$. The number of gestational weeks at delivery was $38.9 \pm 0.8$ in the controls and $35.2 \pm 0.8$ in the cases $(p<0.001)$. Other characteristics did not differ between the cases and controls due to the use of matched pairs between the two groups.

The incidence of developmental delays in the cases and controls is demonstrated in Table 2. The incidence of all types of developmental delays was $6.6 \%$ in the cases, compared with $4.3 \%$ in the controls $(p=0.429)$. The developmental delays were classified as having the characteristics of pervasive developmental disorder (PDD), attention deficit hyperactivity disorder (ADHD), language difficulty, motor difficulty or intellectual disability. The incidence of developmental delays did not differ significantly when classified according to the number of gestational weeks at delivery (34, 35 and 36 weeks of gestation; $9.7 \%, 3.2 \%$ and $6.8 \%$, respectively).

The perinatal characteristics of the cases with developmental delays at 3 years of age are demonstrated in Table 3. Among the cases, we found one patient with an Apgar score of 7 at one minute (Case 1) and two patients with a low birth weight (Case 2, Case 3). Meanwhile, among the controls, we found one patient with an Apgar score of 1/1 (Case 1), one patient with an Apgar score of 7 at one minute (Case 2) and two patients with a low birth weight (Case 3, Case 4). No severe perinatal complications were observed among the other subjects.

\section{Discussion}

In the present study, the incidence of developmental delays at 3 years of age was $6.6 \%$ in the late preterm children and $4.3 \%$ in the full-term children matched for perinatal characteristics. Matching the perinatal characteristics of the subjects, the incidence of developmental delays was similar between the two groups; however, the number of candidates was too small to clarify the differences. Further research is thus needed to investigate the incidence of developmental delays in late preterm children. At the neonatal demographics, Gestational weeks at delivery and Birth weight were significantly different between two groups. The reason is that cases were born at late preterm period, and controls were born at full term.

Late preterm children have been shown to have more neuro developmental problems, such as developmental

Table 1. Maternal and neonatal demographics.

\begin{tabular}{cccc}
\hline & Controls n $=163$ & Cases n = 121 & p-value \\
\hline Maternal & $34.7 \pm 4.7$ & $33.1 \pm 4.2$ & 0.214 \\
Age at delivery (y.o) & $1(0-6)$ & $1(0-6)$ & 0.886 \\
Gravitas & $0(0-3)$ & $0(0-3)$ & $<0.001^{*}$ \\
Parity & & & 0.811 \\
Neonatal & & & $<0.001^{*}$ \\
Gestational weeks at delivery & $38.9 \pm 0.8$ & $35.2 \pm 0.8$ & 0.811 \\
Cesarean section & $47.2 \%(77)$ & $48.8 \%(59)$ & 0.858 \\
Birth weight (g) & $2900 \pm 429$ & $2289 \pm 469$ & 0.811 \\
Birth weight $<$ 10th percentile & $24.5 \%(40)$ & $24.8 \%(30)$ & $13.2 \%(16)$ \\
Birth weight $<$ 3th percentile 12.3\% (20) & $12.3 \%(20)$ & $51.2 \%(62)$ & 0.781 \\
Male & $52.7 \%(86)$ & $8(1-10)$ & 0.713 \\
Apgar score 1 min & $8(1-10)$ & $9(1-10)$ & 0.075 \\
Apgar score 5 min & $9(1-10)$ & $7.31 \pm 0.09$ & 0.414 \\
Umbilical artery pH & $7.29 \pm 0.08$ & $7.4 \%(9)$ & \\
Umbilical artery pH $<7.2$ & $11.5 \%(18)$ & & \\
\hline
\end{tabular}

The data are presented as the mean \pm standard deviation, median (range) or frequency. ${ }^{*} p<0.05$. 
Table 2. Incidence of developmental delays at 3 years of age.

\begin{tabular}{|c|c|c|c|}
\hline & Controls $n=163$ & Cases $n=121$ & $p$-value \\
\hline Developmental delay at 3 years old & $4.3 \%(7)$ & $6.6 \%(8)$ & 0.429 \\
\hline \multicolumn{4}{|l|}{ Developmental characteristics } \\
\hline Pervasive developmental disorder & $0.6 \%(1)$ & $1.7 \%(2)$ & 0.577 \\
\hline Attention deficit hyperactivity disorder & $0 \%(0)$ & $0.8 \%(1)$ & 0.426 \\
\hline Language difficulty & $2.5 \%(4)$ & $0.8 \%(1)$ & 0.398 \\
\hline Motor difficulty & $0 \%(0)$ & $1.7 \%(2)$ & 0.181 \\
\hline Intellectual disability & $1.2 \%(2)$ & $1.7 \%(2)$ & 0.763 \\
\hline \multicolumn{4}{|l|}{ Gestational weeks at delivery } \\
\hline $34(\mathrm{n}=31)$ & & $9.7 \%(3)$ & \\
\hline $35(\mathrm{n}=31)$ & & $3.2 \%(1)$ & \\
\hline $36(n=59)$ & & $6.8 \%(4)$ & \\
\hline $38(n=68)$ & $2.9 \%(2)$ & & \\
\hline $39(n=46)$ & $8.7 \%(4)$ & & \\
\hline $40(n=49)$ & $2.0 \%(1)$ & & \\
\hline
\end{tabular}

Table 3. Perinatal characteristics of the patients with developmental delays at 3 years of age.

\begin{tabular}{|c|c|c|c|c|c|c|c|}
\hline \multicolumn{8}{|c|}{ Cases } \\
\hline Case & Age & $\begin{array}{c}\text { Gestational weeks at } \\
\text { delivery }\end{array}$ & $\begin{array}{l}\text { Birth weight } \\
\text { (g) }\end{array}$ & $\begin{array}{l}\text { Gender } 1 / 5 \\
\min \end{array}$ & Apgar score & UmA pH & $\begin{array}{l}\text { Mode of } \\
\text { delivery }\end{array}$ \\
\hline 1 & 32 & 36 & 2293 & male & $7 / 9$ & 7.36 & $\mathrm{C} / \mathrm{S}$ \\
\hline 2 & 38 & 34 & $1511^{\ddagger}$ & male & $8 / 9$ & 7.27 & $\mathrm{C} / \mathrm{S}$ \\
\hline 3 & 25 & 34 & $1695^{\dagger}$ & female & $8 / 9$ & 7.23 & $\mathrm{C} / \mathrm{S}$ \\
\hline 4 & 27 & 36 & 2390 & male & $8 / 9$ & 7.34 & TV \\
\hline 5 & 35 & 35 & 2431 & male & $8 / 9$ & 7.35 & TV \\
\hline 6 & 36 & 36 & 2912 & male & $8 / 10$ & 7.24 & $\mathrm{TV}$ \\
\hline 7 & 24 & 36 & 3651 & male & $8 / 9$ & 7.40 & TV \\
\hline 8 & 33 & 34 & 2340 & male & $9 / 9$ & 7.40 & TV \\
\hline \multicolumn{8}{|c|}{ Controls } \\
\hline Case & Age & $\begin{array}{c}\text { Gestational weeks at } \\
\text { delivery }\end{array}$ & $\begin{array}{l}\text { Birth weight } \\
\text { (g) }\end{array}$ & $\begin{array}{l}\text { Gender } 1 / 5 \\
\text { min }\end{array}$ & Apgar score & UmA pH & $\begin{array}{l}\text { Mode of } \\
\text { delivery }\end{array}$ \\
\hline 1 & 33 & 39 & 3385 & male & $1 / 1$ & 6.95 & $\mathrm{C} / \mathrm{S}$ \\
\hline 2 & 40 & 40 & 3102 & male & $7 / 8$ & 7.16 & TV \\
\hline 3 & 35 & 39 & $2234^{\ddagger}$ & female & $8 / 9$ & 7.27 & TV \\
\hline 4 & 31 & 39 & $2269^{\ddagger}$ & male & $8 / 9$ & 7.34 & $\mathrm{TV}$ \\
\hline 5 & 41 & 38 & 3105 & male & $8 / 9$ & 7.35 & $\mathrm{C} / \mathrm{S}$ \\
\hline 6 & 41 & 38 & 2887 & male & $8 / 9$ & 7.30 & $\mathrm{C} / \mathrm{S}$ \\
\hline 7 & 33 & 39 & 3328 & male & $8 / 9$ & 7.43 & TV \\
\hline
\end{tabular}

${ }^{\ddagger}$ Birth weight < 3rd percentile, ${ }^{\dagger}$ Birth weight $<$ 10th percentile, UmA: Umbilical artery, Mode of delivery: Method of childbirth (Cesarean section or transvaginal delivery). C/S: Cesarean section, TV: Transvaginal delivery. 
delays, inferior academic performance and behavioral problems [1]-[3]. Kappellou et al. analyzed magnetic resonance images of brain growth and found that the cortical surface area increased 50\% from 34 to 36 weeks of gestation [4]. In addition, Guihard et al. measured the brain weight of dead fetuses and neonates and documented that the brain weight increased 1.5 times during the same period [5].

This study is associated with several limitations. Although all perinatal treatment was administered at a single hospital and the perinatal characteristics were accurately and appropriately matched between the two study groups, the presence of a development delay was assessed solely based on the results of the questionnaires sent to the families by mail, with a low response rate. However, to date, this study is the first to compare long-term developmental outcomes between late preterm children and full-term children with respect to perinatal complications in Japan. We believe that our findings provide new insight into the management of pregnant females in the preterm period as a pilot study.

It is well known that there is an association between developmental delays and both fetal growth restriction [6] [7] and neonatal asphyxia [8] [9]. Nevertheless, in our study, we identified full-term children with developmental delays without a history of perinatal or neonatal complications (Table 3). Developmental outcomes are influenced by various factors in the environment inside the uterus and during the period after birth, as well as the intrapartum period. Further studies assessing long-term developmental outcomes in association with gestational age and the incidence of perinatal complications are needed to determine the appropriate timing of delivery with regard to good long-term neonatal outcomes.

\section{Disclosure}

We declare that all authors have no conflicts of interest relevant to this article.

\section{Acknowledgements}

This study was supported by Department of Obstetrics and Gynecology, Showa University, School of Medicine.

\section{References}

[1] Petrini, J.R., Dias, T., McCormick, M.C., Massolo, M.L., Green, N.S. and Escobar, G.J. (2009) Increased Risk of Adverse Neurological Development for Late Preterm Infants. The Journal of Pediatrics, 154, 169-176.e3. http://dx.doi.org/10.1016/j.jpeds.2008.08.020

[2] Chyi, L.J., Lee, H.C., Hintz, S.R., Gould, J.B. and Sutcliffe, T.L. (2008) School Outcomes of Late Preterm Infants: Special Needs and Challenges for Infants Born at 32 to 36 Weeks Gestation. The Journal of Pediatrics, 153, 25-31. http://dx.doi.org/10.1016/j.jpeds.2008.01.027

[3] Morse, S.B., Zheng, H., Tang, Y.W. and Roth, J. (2009) Early School-Age Outcomes of Late Preterm Infants. Pediatrics, 123, e622-e629. http://dx.doi.org/10.1542/peds.2008-1405

[4] Kapellou, O., Counsell, S.J., Kennea, N., Dyet, L., Saeed, N., Stark, J., et al. (2006) Abnormal Cortical Development after Premature Birth Shown by Altered Allometric Scaling of Brain Growth. PLoS Medicine, 3, e265. http://dx.doi.org/10.1371/journal.pmed.0030265

[5] Guihard-Costa, A.M. and Larroche, J.C. (1990) Differential Growth between the Fetal Brain and Its Infratentorial Part. Early Human Development, 23, 27-40. http://dx.doi.org/10.1016/0378-3782(90)90126-4

[6] Lundgren, E.M. and Tuvemo, T. (2008) Effects of Being Born Small for Gestational Age on Long-Term Intellectual Performance. Best Practice \& Research Clinical Endocrinology \& Metabolism, 22, 477-488. http://dx.doi.org/10.1016/j.beem.2008.01.014

[7] Bergvall, N., Iliadou, A., Johansson, S., Tuvemo, T. and Cnattingius, S. (2006) Risks for Low Intellectual Performance Related to Being Born Small for Gestational Age Are Modified by Gestational Age. Pediatrics, 117, e460-e467. http://dx.doi.org/10.1542/peds.2005-0737

[8] Stuart, A., Otterblad Olausson, P. and Källen, K. (2011) Apgar Score at 5 min after Birth in Relation to School Performance at 16 Years of Age. Obstetrics \& Gynecology, 118, 201-208. http://dx.doi.org/10.1097/AOG.0b013e31822200eb

[9] Moster, D., Lie, R.T. and Markstad, T. (2002) Joint Association of Apgar Scores and Early Neonatal Symptoms with Minor Disability at School Age. Archives of Disease in Childhood. Fetal and Neonatal Edition, 86, F16-F21. 